\title{
Fusarium meridionale is more aggressive and competitive than $F$. graminearum as a causal agent of Gibberella Ear Rot of maize in Brazil
}

Franklin J. Machado ${ }^{1,2^{\star}}$, Paulo R. Kuhnem ${ }^{3,6^{\star}}$, Ricardo T. Casa ${ }^{4}$, Nicole McMaster ${ }^{5}$, David G. Schmale III $^{5}$, Lisa J. Vaillancourt ${ }^{2}$, Emerson M. Del Ponte ${ }^{1}$

1 Departamento de Fitopatologia, Universidade Federal de Viçosa, Viçosa MG, Brazil; ${ }^{2}$ Department of Plant Pathology, University of Kentucky, Lexington KY, United States; ${ }^{3}$ Programa de Pós-graduação em Fitotecnia, Universidade Federal do Rio Grande do Sul, Porto Alegre RS, Brazil; ${ }^{4}$ Universidade do Estado de Santa Catarina, Lages SC, Brazil $;{ }^{5}$ School of Plant and Environmental Sciences, Virginia Tech, Blacksburg VA, United States; ${ }^{6}$ Current address: Biotrigo Genética Ltda, Passo Fundo RS, Brazil

* These authors contributed equally to this work

Authors for correspondence: Emerson M. Del Ponte, e-mail: delponte@ufv.br; Lisa J. Vaillancourt, e mail: vaillan@uky.edu

\section{Abstract}

In Brazil, Gibberella ear rot (GER) of maize is caused mainly by Fusarium meridionale (Fmer), while F. graminearum (Fgra) is a minor contributor. To test the hypothesis that Fmer is more aggressive than Fgra on maize, three experiments were conducted in the south (subtropical summer), and one in the central-south (tropical winter) of Brazil, totaling seven conditions (year $\times$ location $\times$ hybrid). Treatments consisted of Fgra or Fmer (two isolates of each) inoculated once four days after silk; alternately inoculated (FgranFmer or FmernFgra) six days apart; and (in central-south only) sequentially inoculated without alternating (FmernFmer or FgranFgra). Overall GER severity was higher in the south (37.0\%) compared with the central-south $(16.9 \%)$, likely due to the higher summer temperatures $\left(20\right.$ to $\left.25^{\circ} \mathrm{C}\right)$. In the south, severity was highest in Fmer treatments (67.8\%); followed by FmeraFgra (41.1\%); then FgranFmer (19.4\%); 
and lowest in Fgra (2.1\%), suggesting an antagonistic relationship. In the central-south during winter $\left(15\right.$ to $\left.20^{\circ} \mathrm{C}\right)$, severity was generally higher (7.3 to 11.6\%) in sequential inoculation treatments than when either species was inoculated alone. Only nivalenol (NIV) or deoxynivalenol (DON) were detected when Fmer or Fgra, respectively, were inoculated singly and sequentially with no alternation. Both toxins were found in grains harvested from the FmeraFgra treatment, while only NIV was found in kernels from the FgranFmer treatment, suggesting that Fmer was more competitive than Fgra in co-inoculations. The dominance of Fmer as a cause of GER in Brazil may be due in part to its higher aggressiveness and competitiveness than Fgra.

\section{KEYWORDS:}

Zea mays, Fusarium graminearum species complex, nivalenol.

\section{Introduction}

Several species within the Fusarium graminearum species complex (FGSC) are the cause of major diseases of winter and summer cereal crops including Fusarium head blight (FHB) in wheat (McMullen et al. 2012) and Gibberella ear rot (GER) and stalk rot (GSR) in maize (Goswami and Kistler 2004; Munkvold 2003b). FGSC species are particularly common as cereal pathogens in the subtropical climate of southern Brazil where wheat is grown during the winter-spring, and maize during the summer-fall seasons. GER is reportedly favored by increased levels of moisture around silking, followed by moderate 
temperatures and high rainfall during the maturation period (Munkvold 2003b; Sutton 1982).

Both FHB in wheat and barley and GER in maize reduce yield (Duffeck et al. 2019; Munkvold 2003a), but the presence of mycotoxins that accumulate in the kernels and downgrade product value is also a major concern (Munkvold et al. 2019). FGSC species produce several mycotoxins: the most important ones belong to the B-trichothecene group, including nivalenol (NIV), and deoxynivalenol (DON) and its acetylated derivatives 3ADON and 15ADON (Miller and Greenhalgh 1991). These mycotoxins can accumulate in grain at levels considered unsafe for both livestock and human consumption, posing a serious threat to food safety (Pestka 2010; Rocha et al. 2005). To mitigate the impact on animal and human health, maximum tolerated limits have been established for Fusarium mycotoxins in wheat and maize grain and byproducts in Brazil and worldwide (ANVISA 2011; van Egmond et al. 2007). In Brazil, DON, zearalenone (ZEA) and fumonisins (B1 and B2) are the only mycotoxins that are currently regulated for maize (ANVISA 2011; 2017).

Management of GER aims to reduce infection by toxigenic fungi in order to increase yield and suppress mycotoxin contamination (Munkvold 2003a). The most effective control for GER is the use of host genetic resistance. However, breeding for resistance is complicated by the diversity of Fusarium species that can cause GER (Mesterházy et al. 2012; Munkvold 2003a). Complete resistance to GER has not been reported and the mechanisms underlying resistance are not completely understood (Mesterházy et al. 2012). In fact, when each of the 14-most planted maize hybrids in southern Brazil was challenged with F. 
meridionale (Fmer), the most common FGSC species isolated from maize (Kuhnem et al. 2016), none was resistant to GER (Nerbass et al. 2015). The use of foliar fungicides to control maize diseases (Esker et al. 2018), including ear rots, has increased in recent years (Andriolli et al. 2016; Anderson et al. 2017; Luna and Wise 2015; Fingstag et al. 2019). Nonetheless, trichothecene mycotoxins typically produced by GER pathogens have recently been found contaminating commercial maize grain in Brazil (Oliveira et al. 2017).

Regional shifts in host dominance among FGSC species causing FHB in wheat and GER in maize have been reported, including in South American wheat-growing regions (Castañares et al. 2016; Del Ponte et al. 2015; Gomes et al. 2015; Kuhnem et al. 2016; Sampietro et al. 2011). For example, F. graminearum (Fgra) of the DON/15ADON genotype is the most prevalent species causing FHB in wheat and barley in South America, and worldwide (Del Ponte et al. 2015; Kelly and Ward 2018). In North America, GER is also caused mainly by Fgra of the DON/15ADON type, according to a survey conducted in Ontario, Canada (Burlakoti et al. 2017). Fusarium boothii, another DON/15ADON-producing species, was reported as the primary cause of GER in South Africa (Boutigny et al. 2011). In Brazil, Fmer, a NIV-producing species, is the dominant FGSC species in maize, and is also increasing in importance in wheat in regions where maize is a major crop (Del Ponte et al. 2015; Pereira et al. 2021). Other NIV-producing FGSC species (F. asiaticum, F. cortaderiae and F. austroamericanum) and also some non-NIV, non-FGSC species (F. culmorum, F. cerealis and F. poae) have been found in association with GER in maize in other regions of the world 
(Basler 2016; Desjardins and Proctor 2011; Kuhnem et al. 2016; Lee et al. 2012; Ndoye et al. 2012; Zhang et al. 2016).

The toxin profile of different FGSC species has been considered to influence pathogenesis (Ward et al. 2002). A recent survey of mycotoxins contaminating maize grains in southern Brazil was consistent with previous work suggesting that Fmer was the primary maize pathogen. Authors of that study reported the presence of NIV, which is produced by Fmer, and rarely by Fgra, in more samples (76\%) than DON (48\%), though levels for both were lower than the Brazilian limits of contamination for DON (Oliveira et al. 2017). While DON has been confirmed as an aggressiveness factor that facilitates fungus spread within wheat heads and, to a lesser extent, in maize ears in several studies (Bai et al. 2002; Desjardins et al. 1996; Harris et al. 1999; Maier et al. 2006), the role of NIV in the infection and spread of the disease within maize ears remains unclear (Maier et al. 2006). There are very few studies that have investigated differential aggressiveness among members of the FGSC with different toxin profiles that cause GER.

Multiple members of the FGSC and of other Fusarium species complexes can co-occur in the same field, or even on the same maize ear (Logrieco et al. 2002; Oldenburg et al. 2017; Picot et al. 2012). Previous studies have investigated interactions between Fgra and Fusarium spp. in maize ears (Picot et al. 2012; Reid et al. 1999); however the effects of any interspecific interaction between FGSC members on GER development are unknown. In contrast, intra- and inter-species competition interactions, including antagonistic intrapopulation interactions, have been demonstrated for FHB pathogens on wheat heads and in 
vitro (Vaughan et al. 2020; Walkowiak et al. 2015; Wagacha et al. 2012; Miedaner et al. 2004; Siou et al. 2015; Xu et al. 2007).

We hypothesized that (1) strains of Fmer are more aggressive and competitive and (2) produce significantly greater levels of NIV trichothecenes in maize ears, when compared with Fgra strains. Isolates were inoculated singly, and they were also inoculated alternately and sequentially (six days apart), to study interspecific interactions. We conducted experiments at three different locations with contrasting weather patterns, mainly temperature. The results of this study could help to explain why Fmer dominates as the GER pathogen of maize in Brazil.

\section{Material and Methods}

\section{Fungal isolates and preparation of inoculum}

Two Fgra (DON/15ADON-producing) isolates and two Fmer (NIV-producing) isolates were selected from a collection obtained from symptomatic maize kernels (Stumpf et al. 2013). These isolates had been identified to species as part of a previous study that demonstrated the dominance of Fmer in Brazilian maize (Kuhnem et al. 2016).

A spore suspension was prepared by growing isolates individually on potato dextrose agar (PDA) for 10 days with a 12-h dark/light cycle. The macroconidia were filtered through two layers of cheesecloth to reduce the number of mycelial fragments present in the inoculum. The macroconidial suspensions of each isolate were quantified by using a hemocytometer. Spore 
suspensions of the two isolates for each species were diluted in sterile water and then mixed in a 1:1 ratio $(\mathrm{v} / \mathrm{v})$ to achieve the desired concentrations $\left(5 \times 10^{5}\right.$ macroconidia/ml) (Reid et al. 1995).

\section{Treatments and inoculation procedures}

Each species was inoculated individually, at four days after silking (Reid et al. 2002). Two other treatments consisted of alternate inoculations of the two species (the second six days after the first), for a total of four pathogen inoculation treatments [Fgra; Fmer; FgranFmer; FmernFgra]. In one location only, the two species were also inoculated sequentially, six days apart (FgranFgra; FmeraFmer). A mock inoculation (sterile distilled water) was included as a negative control (Table 1). Plants were individually inoculated by using a syringe with an obtuse needle to inject the suspensions $\left(2 \mathrm{ml}\right.$ of a $5 \times 10^{5}$ macroconidia/ml solution) into the silk channel of the primary ear (Anderson et al. 2016). Inoculations were followed by three consecutive days of irrigation.

\section{Experimental field design}

The inoculation treatments were evaluated under field conditions on ear-rot susceptible commercial hybrids (P30F53 $\mathrm{HR}^{\circledR}$, STATUS TL ${ }^{\circledR}$, and RB9004 PRO2 ${ }^{\circledR}$ ) in two regions in Brazil with distinct climatic patterns. The field trials were arranged in a randomized complete block design with four replications, and each of the five inoculation treatments was randomly assigned to the experimental units. 
Table 1. Single and sequential inoculation of Fusarium graminearum (Fgra) and Fusarium meridionale (Fmer) in the early stages of silk development of maize ears.

\begin{tabular}{|c|c|c|}
\hline Treatment $^{\mathbf{a}}$ & Silking +4 days & Silking + 10 days \\
\hline Fgra $^{\mathbf{b}}$ & Fgra & - \\
\hline Fmer $^{\mathrm{c}}$ & Fmer & - \\
\hline FgranFmer & Fgra & Fmer \\
\hline FmernFgra & Fmer & Fgra \\
\hline FgranFgra $^{\mathrm{d}}$ & Fgra & Fgra \\
\hline FmeroFmer & Fmer & Fmer \\
\hline Mock inoculations & Water & Water \\
\hline \multicolumn{3}{|c|}{$\begin{array}{l}{ }^{a} \text { All inoculations were done by injecting } 2 \mathrm{~mL} \text { of the macroconidia suspension at } 5 \times 10^{5} \\
\text { macroconidia/ml. All isolates were obtained from naturally infected maize kernels (Stumpf et al. } \\
\text { 2013). Isolate codes: Fmer: 09Mi034 and 09Mi085; Fgra: 09Mi010 and 09Mi011 } \\
\text { bix of two F. graminearum (15ADON) isolates. } \\
{ }^{\mathrm{c}} \text { Mix of two F. meridionale (NIV) isolates. } \\
\text { d,e Treatments evaluated only in the Viçosa/MG trial. }\end{array}$} \\
\hline
\end{tabular}

In the south subtropical region, the experiments were conducted $400 \mathrm{~km}$ apart in two municipalities in each of two Brazilian states during the 2011/2012 and 2012/2013 maize growing seasons (Table 2). The hybrids P30F53 $\mathrm{HR}^{\circledR}$ and STATUS TL ${ }^{\circledR}$ were compared in these experiments. The inoculation treatments were randomly assigned to one row (6-m-long row with $50 \mathrm{~cm}$ between rows) in each replicate (block). The ten central plants (comprising an experimental unit) of each row were inoculated. Inoculated rows were bordered by uninoculated plants of the same variety. Fertilization and weed control were performed following local recommendations. The plots were sprinkle-irrigated as needed. 
In the tropical south-central region of Brazil, an experiment was conducted at the experimental station of the Universidade Federal de Viçosa, during the 2017 winter growing season (Table 2). Seeds of the maize hybrid RB9004 PRO2 ${ }^{\circledR}$ were sown in April. The experimental unit consisted of a 5-m-long row (60 $\mathrm{cm}$ between rows) with 18 plants. The central ten plants in each row were inoculated. Inoculated rows were bordered by uninoculated plants of the same variety. The entire field was fertilized following chemical soil analyses, and sprinkle-irrigated as needed.

In each of the three sites, daily summaries of relative humidity and temperature were measured at meteorological stations located within $500 \mathrm{~m}$ of distance to the experimental (Figure S6). We did not collect rainfall data, as the trials received irrigation.

Table 2. Summary information of the three trials conducted in the south (subtropical summer) and one conducted in the central-south (tropical winter) of Brazil during 2012, 2013 and 2017 harvest seasons.

\begin{tabular}{|c|c|c|c|c|c|c|c|}
\hline Location $^{a}$ & Latitude & Longitude & Alt (m) & Hybrid & $\begin{array}{l}\text { Planting } \\
\text { date }\end{array}$ & $\begin{array}{l}\text { Inoculation } \\
\text { date }\end{array}$ & $\begin{array}{l}\text { Harvest } \\
\text { date }\end{array}$ \\
\hline $\begin{array}{l}\text { Lages } \\
\text { SC }\end{array}$ & $27^{\circ} 47^{\prime} 34^{\prime \prime} \mathrm{S}$ & $50^{\circ} 18^{\prime} 15^{\prime \prime} \mathrm{W}$ & 940 & $\begin{array}{l}\text { P30F53 HR } \\
\text { STATUS TL }\end{array}$ & 14 Nov 11 & $\begin{array}{l}17 \text { to } \\
20 \text { Jan } 12\end{array}$ & 9 Mar 12 \\
\hline $\begin{array}{l}\text { Eldorado } \\
\text { RS }\end{array}$ & $30^{\circ} 05^{\prime} 31^{\prime \prime} \mathrm{S}$ & $51^{\circ} 40^{\prime} 19^{\prime \prime} \mathrm{W}$ & 046 & $\begin{array}{l}\text { P30F53 HR } \\
\text { STATUS TL }\end{array}$ & 3 Oct 11 & $\begin{array}{l}2 \text { to } \\
3 \text { Jan } 12\end{array}$ & 9 Mar 12 \\
\hline $\begin{array}{l}\text { Eldorado } \\
\text { RS }\end{array}$ & $30^{\circ} 05^{\prime} 31^{\prime \prime} \mathrm{S}$ & $51^{\circ} 40^{\prime} 19^{\prime \prime} \mathrm{W}$ & 046 & $\begin{array}{l}\text { P30F53 HR } \\
\text { STATUS TL }\end{array}$ & 1 Oct 12 & 26 Dec 12 & $\begin{array}{l}20 \mathrm{Feb} \\
13\end{array}$ \\
\hline $\begin{array}{l}\text { Viçosa } \\
\text { MG }\end{array}$ & $20^{\circ} 44^{\prime} 44^{\prime \prime} \mathrm{S}$ & $42^{\circ} 50^{\prime} 59^{\prime \prime} \mathrm{W}$ & 661 & $\begin{array}{l}\text { RB9004 } \\
\text { PRO2 }^{\circledR}\end{array}$ & 25 Apr 17 & 07 Ago 17 & 25 Set 17 \\
\hline
\end{tabular}

${ }^{a}$ Municipality and State of Brazil where the trials were carried out. South region (subtropical summer): $\mathrm{SC}=$ Santa Catarina and RS = Rio Grande do Sul states. Central-south (tropical winter): MG = Minas Gerais state. 


\section{Disease and mycotoxin assessment}

When grain moisture content reached $22 \%$ for the southern subtropical trials, or physiological maturity stage for the south-central tropical trial, the ten inoculated ears for each treatment were handpicked and husked. The GER severity on each ear was rated as the percentage area of the ear covered with fungal mycelia (Reid et al. 2002; Reid and Zhu 2005).

Trichothecenes and ZEA mycotoxins were measured in maize kernels from the Viçosa trials. Harvested maize ears were dried at $60{ }^{\circ} \mathrm{C}$ for five consecutive days, shelled, and grains were stored dry at $-20{ }^{\circ} \mathrm{C}$ until analysis. Mycotoxin in grains was determined by bulking the individual ears from each block, which was considered as a replicate. A 10-g sub-sample of each pooled replicate was ground by using a coffee grinder and then homogenized. The ground samples were sent to the Schmale Lab at Virginia Tech in Blacksburg (Virginia). The amount of DON and each of its acetylated forms (15ADON and 3ADON), NIV, and ZEA were quantified using gas chromatography-mass spectrometry (Fuentes et al. 2005; Mirocha et al. 1998).

\section{Data analysis}

A single multilevel (hierarchical or linear mixed) model was fitted to the GER severity data from the southern trials (Eldorado and Lages). The main reasons for using the multilevel model included 1) observational units could not be assumed to be independent and 2) inferences can be made to a population of 
groups because groups in the sample are treated as a random sample from a population of groups.

In this modelling framework, multiple random-effects capture how observations deviate within a cluster, and how each cluster deviates from the overall group. A three-level model was then fitted. The effects of interest (the inoculation treatments) were nested by study design, i.e. GER severity was measured on individual maize ears (level 1), nested within the hybrids (level 2), and hybrids were nested within trials (level 3). A model of nested random effects (cultivar within trial) was specified because cultivar was reused across the trials.

For the Viçosa trial, a linear mixed model was fitted to the $\log$-transformed $(\log +0.5)$ GER severity data. Inoculation treatment and block were treated as fixed effects, and individual ears within blocks as random effects.

The simple linear and the multilevel models were fitted using the $1 \mathrm{~m}$ and lmer (lme4 package) functions in $\mathrm{R}$ ( $\mathrm{R}$ Core Team 2020). Different transformations (angular, log and logit) were tested and chosen according to residual analysis. The model residuals were diagnosed using the 'DHARMa' package, which uses a simulation-based approach to create readily interpretable scaled (quantile) residuals for fitted (generalized) linear mixed models (Hartig and Lohse 2020). This package provided P-values for three tests of model quality (normality of residuals, overdispersion and outlier). A type-III analysis-of-variance table was obtained using the Anova function of the car package (Fox and Weisberg 2019). Post hoc analysis was performed using the emmans package to obtain estimated marginal means and respective 95\% 
confidence intervals, and comparisons thereof via pairwise P-value plots (Lenth et al. 2020).

\section{Results}

\section{Southern trials}

GER symptoms were not observed in the non-inoculated controls, suggesting the absence of background inoculum. Symptoms of GER were observed in almost all $(n=204)$ inoculated ears that were visually scored. Visual symptoms were not present in $32 / 204(15.6 \%)$ of the inoculated ears; most of the zeros (60\%) were found in the Fgra inoculation treatments across all six environments (Fig. 1). There was a trend of increasing GER severity when Fmer was inoculated after Fgra or alone. The Fmer treatment, in particular, produced the highest median of GER severity in almost all trials. When Fmer was followed by Fgra inoculation, GER severity tended to decrease. The variability in the severity measures was quite high, and tended to increase with an increase in severity; individual values ranged from zero to $100 \%$ in the same treatment (Fig. 1).

The simulation-based residual analysis did not detect any issue related to distribution, dispersion and outliers with the selected model specification (Fig. S1). The null hypothesis of the effect of inoculation treatment was rejected $\left(\chi^{2}=\right.$ $67.8, \mathrm{P}<0.0001)$. The estimated marginal means (EMMs) of the fitted model ranged from 0.02 (2\%) for Fgra inoculated alone to 0.41 (41\%) for Fmer inoculated alone. Plots for the pairwise Tukey-adjusted P-value (Fig. 2A) and the EMMs and 
95\% confidence interval (Fig. 2B) show that Fmer, and Fmer followed by Fgra, produced statistically similar values of GER severity.

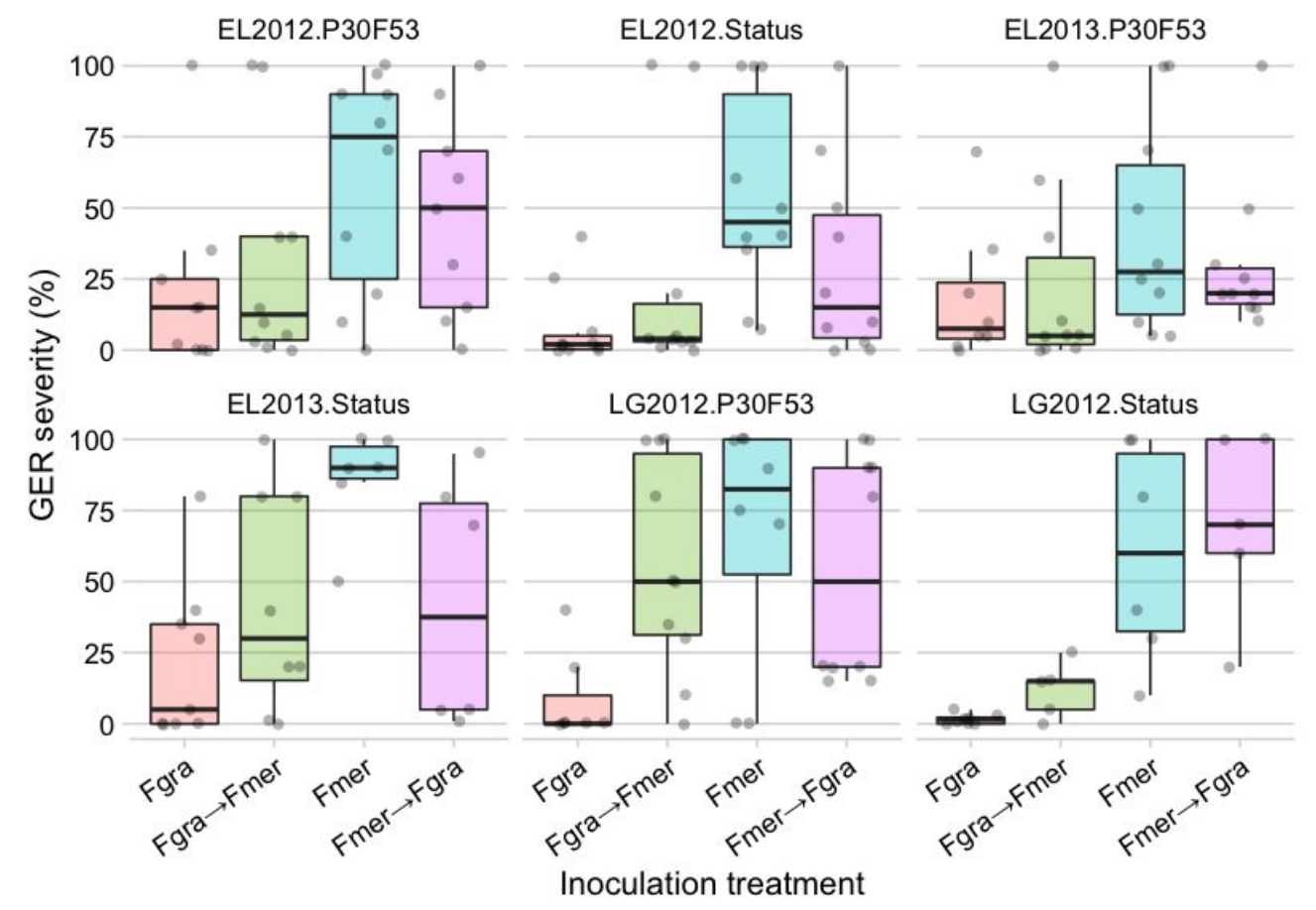

Figure 1. Distribution of Gibberella ear rot (GER) visual severity estimates on individual plants (ear, dot) inoculated with in-field inoculation treatments composed of single-time inoculation of either Fusarium graminearum (Fgra) or F. meridionale (Fmer) or sequential (second inoculation at 6 days after the first) alternated inoculation of the same species in different order (FgranFmer or FmeraFgra). The six environments (plots) correspond to a combination of location $\times$ year $\times$ hybrid $($ EL $=$ Eldorado, RS, Brazil) or LG (Lages, SC, Brazil), harvest seasons (2012 or 2013), and maize hybrids (P30F53 HR $^{\circledR}$ and STATUS $\left.\mathrm{TL}^{\circledR}\right)$. 


\section{Viçosa trial}

Similar to the southern trials, no GER symptoms were found in the non-inoculated controls. GER severity values ranged from zero (4\% of all ears) to $100 \%(0.5 \%$ of all ears). The distribution of the severity values was right-skewed with an overall mean (median) of $16.9 \%(8 \%)$. The log-transformation helped to normalize the distribution of the model residuals (Fig. 3A-B) and stabilize variances (box-plot in Fig. S2). Similar to the southern experiments, there was a considerable variation in the GER severity values within the same block (Fig. 3C).

A

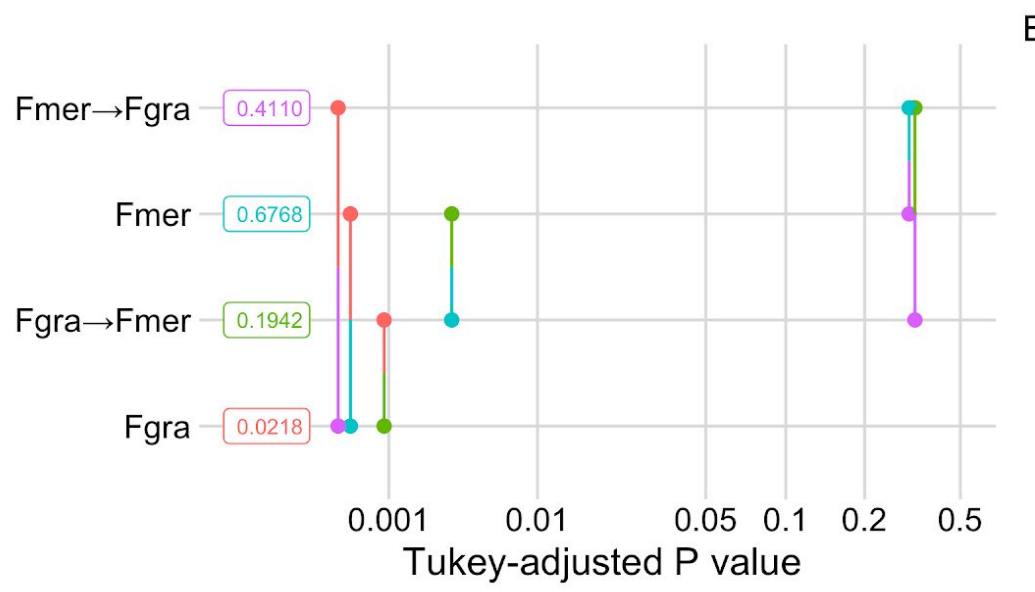

B

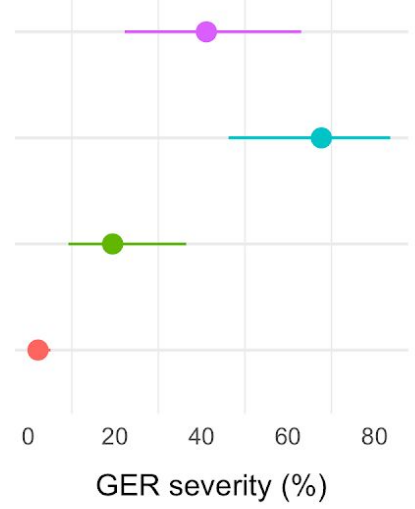

Figure 2. A) Pairwise P-value plot depicting the estimated marginal means (EMMs) (colored proportion values) by a multilevel model fitted for Gibberella ear rot (GER) severity (proportion visible area affected) on maize grown at six location $\times$ year $\times$ hybrid combinations, and the respective probability values for each pairwise comparison. B) EMMs for percent GER values and respective 95\% confidence intervals. 
The simulation-based residual analysis of the fit of the linear model did not show any issues with the chosen transformation $(\log +0.5)$ (Fig. S3). The null hypothesis of the effect of inoculation treatment was rejected $(\mathrm{F}=8.81, \mathrm{P}<$ 0.0001). The estimated marginal means (EMMs) of the fitted model ranged from $2.4 \%$ for Fgra inoculated alone to $11.7 \%$ for Fmer inoculated sequentially.
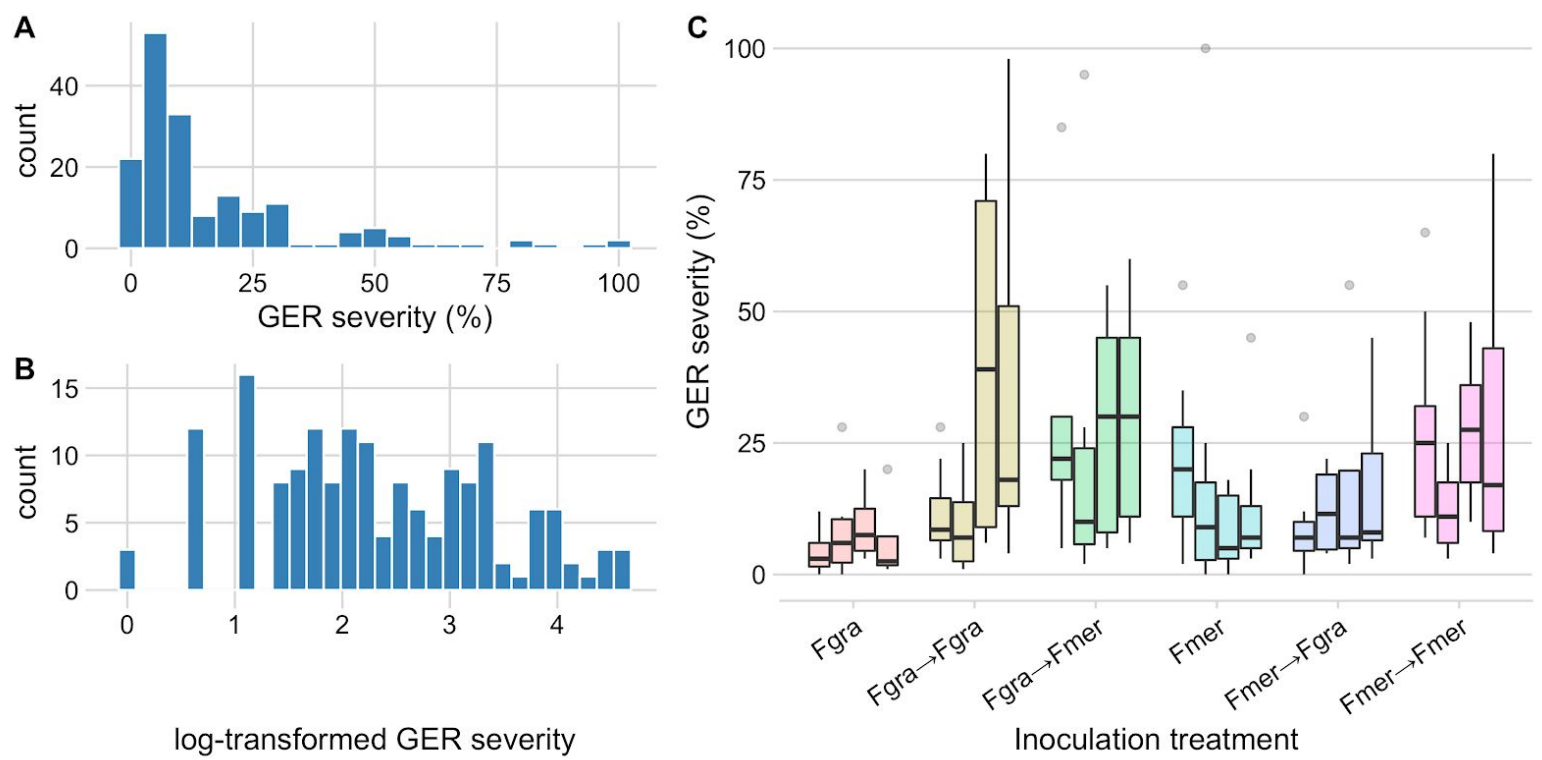

Figure 3. Histograms for the distribution of Gibberella ear rot (GER) visual severity (A) and log-transformed GER severity data (B) for normalizing model residuals. The visual GER severity was estimated on individual plants (each dot represents a single ear), grouped in blocks (6 to 10 ears in a box-plot) inoculated with treatments consisting of a single inoculation of either Fusarium graminearum (Fgra) or F. meridionale (Fmer); sequential (second 6 days after the first) inoculation of the same species (FgranFgra or FmeraFmer); or sequential alternated inoculation of both species (FgranFmer or FmernFgra) C). The RB9004 PRO2 ${ }^{\circledR}$ maize hybrid was cultivated during the 2017 growing season in Viçosa, Minas Gerais state (MG). 
The pairwise Tukey-adjusted P-values (Fig. 4A) plot shows a range of values varying from 0.001 to 1 , with three comparisons around the $5 \%$ significance level. The appraisal of the P-value plot and the plot with the back-transformed means and 95\% confidence interval (Fig. 4B), suggest statistically similar severity for sequential inoculation of the same species (Fmer or Fgra) or when Fmer was inoculated after Fgra. The lowest, statistically similar $(P=0.056)$ GER severity values, were estimated for the two single-time inoculation of either species (Fig. 4A).
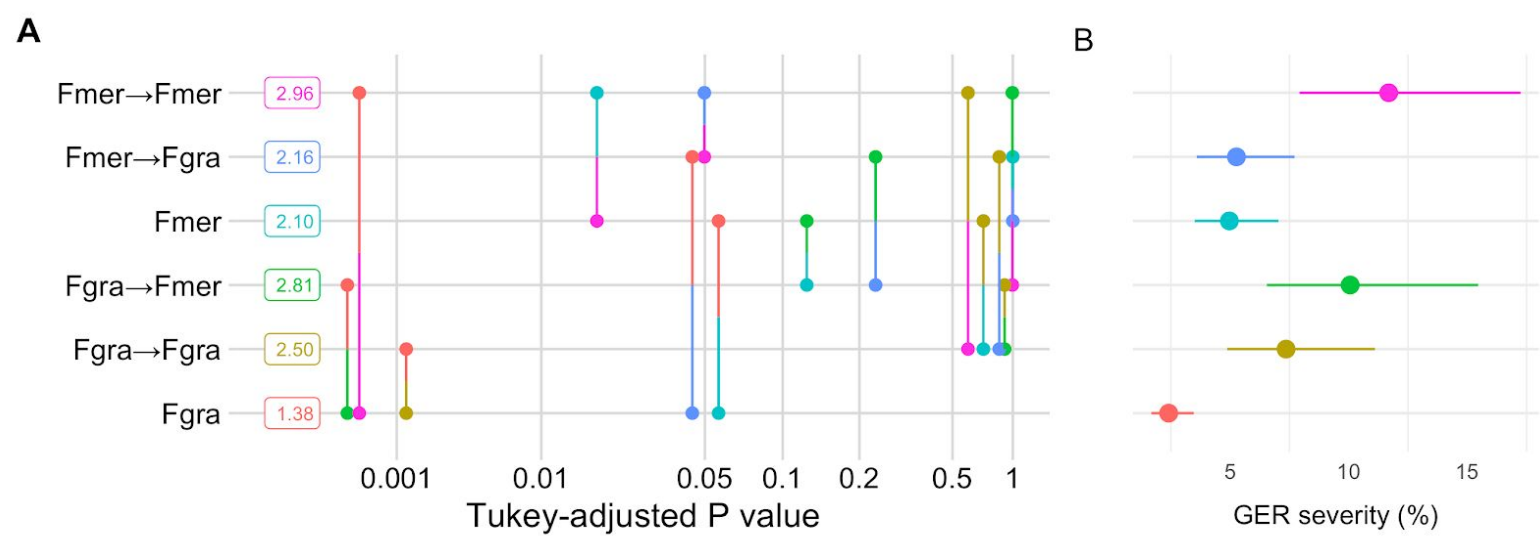

Figure 4. A) Pairwise P-value plot (multiple comparison) depicting the estimates of marginal means (EMMs) by a multilevel model fitted for log-transformed values (shown in color next to the treatment code) of Gibberella ear rot (GER) severity (percent affected area) on maize (RB9004 PRO2 ${ }^{\circledR}$ ) grown grown during the 2017 growing season in Viçosa, Minas Gerais state (MG, Brazil). B) Back-transformed EMMs (percent severity) values and respective 95\% confidence intervals. Treatments were: single-time inoculation of either Fusarium graminearum (Fgra) or F. meridionale (Fmer); sequential (the second 6 days after the first) inoculation of the same species (FgranFgra or FmernFmer); 
and sequential alternated inoculation in different order (FgranFmer or FmeraFgra).

Trichothecene levels in kernels from Fmer and Fgra inoculated singly ranged from 0.50 to $2.05 \mu \mathrm{g} / \mathrm{g}$ (ppm), and from 0.6 to $21.25 \mu \mathrm{g} / \mathrm{g}$ for the two sequential inoculations of either species respectively (Fig. 5). For the sequential alternated inoculation treatments, DON and NIV levels ranged from 0.35 to 3.15 $\mu \mathrm{g} / \mathrm{g}$. DON was detected in only one sample of FmeraFgra at similar levels with NIV and ZEA $(0.60 \mu \mathrm{g} / \mathrm{g}, 0.70 \mu \mathrm{g} / \mathrm{g}$ and $0.40 \mu \mathrm{g} / \mathrm{g}$, respectively). Only NIV was detected in kernels from ears inoculated with Fmer alone, whereas DON was the only mycotoxin detected in kernels from the Fgra treatment. In contrast, NIV was abundant in kernels from ears of the FgranFmer treatment. In the FmeraFgra treatment NIV, DON, and a smaller amount of ZEA were all detected (Fig. 5). For the sequential inoculation of Fgra, DON $(7.96 \mu \mathrm{g} / \mathrm{g})$ was detected in all kernel samples whereas 15ADON $(1.08 \mu \mathrm{g} / \mathrm{g})$ and 3ADON $(0.48 \mu \mathrm{g} / \mathrm{g})$ were detected in half of them (Fig. 5). Finally, five times more NIV was detected in kernels from ears inoculated sequentially with Fmer $(6.15 \mu \mathrm{g} / \mathrm{g})$, compared to the single-time inoculation treatment $(1.25 \mu \mathrm{g} / \mathrm{g})$. There was a clear association between NIV production and GER severity (Fig. 4B and Fig. 5). 


\section{Seasonal temperature and relative humidity}

The daily temperature was variable across the four experiments during the 37-day period relative to the inoculation. In the subtropical summer trials, where the inoculations and the development of the disease occurred during the summer (Dec to Jan), the mean temperatures were generally higher than in the tropical winter, ranging mostly between $20^{\circ} \mathrm{C}$ and $26^{\circ} \mathrm{C}$ in the two low-elevation Eldorado trials. In the high-elevation Lages site, the minimum temperatures were markedly lower than in the Eldorado (Fig. 6).

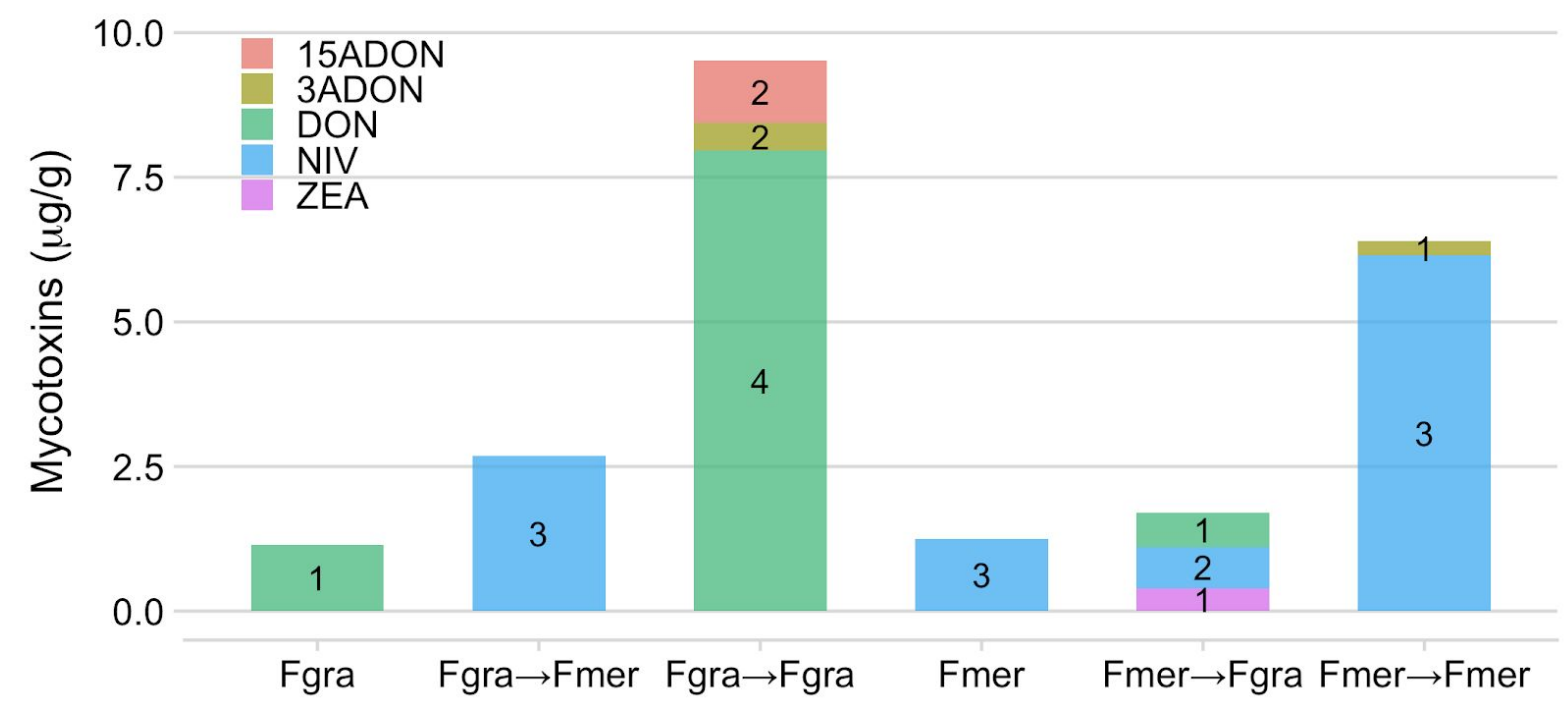

Figure 5. Mean production of deoxynivalenol (DON) and its acetylated forms [15-acetyl-deoxynivalenol (15ADON) and 3ADON], nivalenol (NIV) and zearalenone (ZEA) resulting from Fusarium graminearum and F. meridionale isolates inoculated onto maize ears of hybrid RB9004 PRO2 ${ }^{\circledR}$ in single and sequential inoculation treatments in a field trial conducted in Viçosa 2017. 
Numbers represent how many of the four blocks (bulked sample of kernels from 10 inoculated ears) had detectable mycotoxins. Measurements in the missing blocks were under the limit of detection $(<0.25 \mu \mathrm{g} / \mathrm{g})$.

The relative humidity was slightly lower in 2013 than in 2012 in Eldorado, and inversely related with temperature (Fig. 6). In the Viçosa trial, conducted during a tropical winter, the mean temperature was generally between 15 and $20^{\circ} \mathrm{C}$. The minimum temperatures were the lowest across all the experiments, ranging from 8 to $11^{\circ} \mathrm{C}$. The relative humidity was also the lowest (Fig. S4), although the plots received supplemental irrigation.
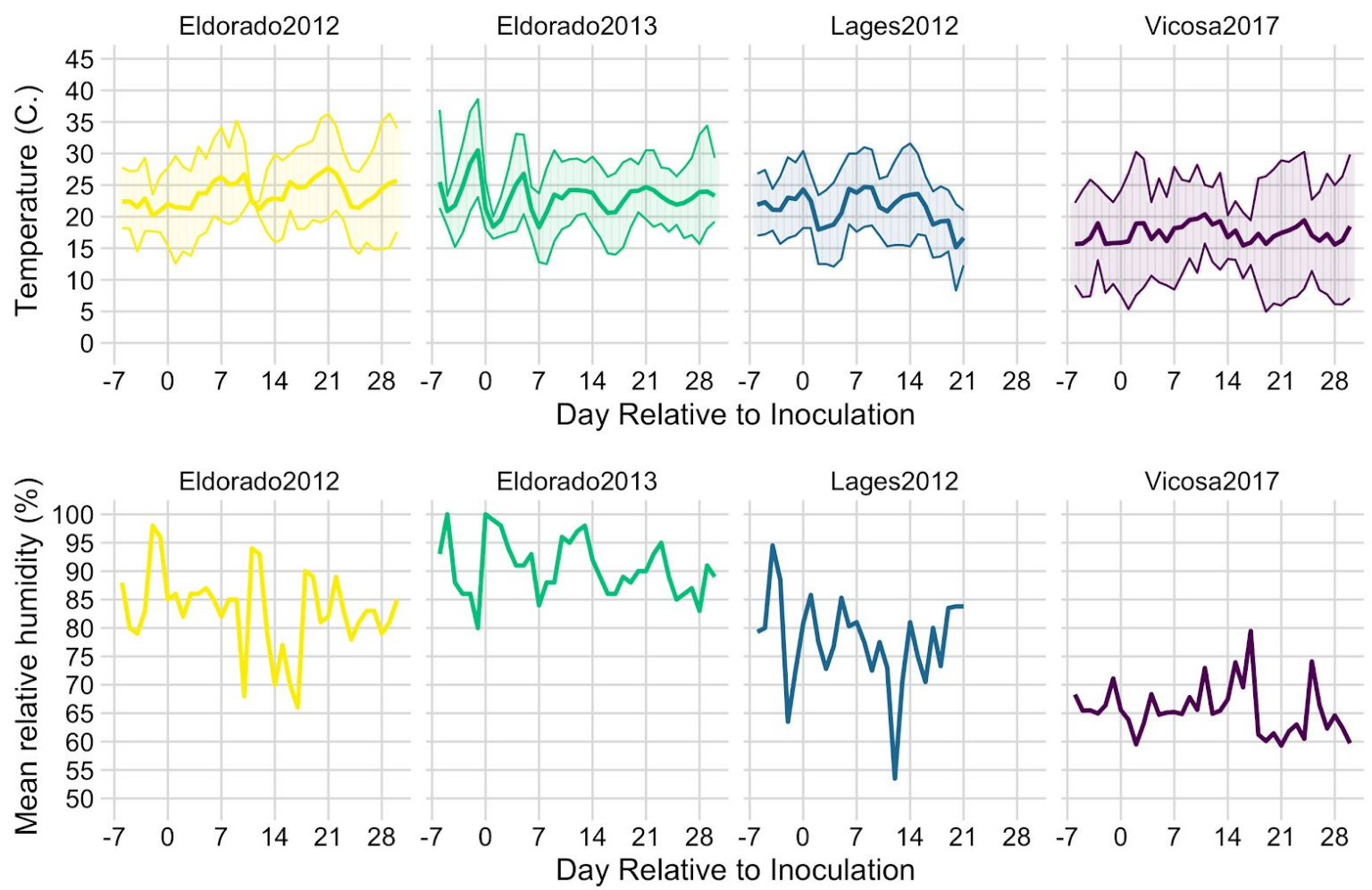

Figure 6. Daily values temperature (minimum, mean and maximum) and relative humidity recorded at the nearest meteorological station during the maize inoculation experiment conducted at four experimental sites in southern (Eldorado and Lages) and central-eastearn (Viçosa) Brazil during three seasons. 


\section{Discussion}

New information is needed to understand why different phylogenetic species within the FGSC are dominant among isolations from different cereals, or from the same cereal in different regions of the world (Boutigny et al. 2011; Carter et al. 2000; Castañares et al. 2016; Del Ponte et al. 2015; Gomes et al. 2015; Kuhnem et al. 2016; Sampietro et al. 2011; Umpiérrez-Failache et al. 2013). Overall, Fgra is the most common cause of FHB in wheat and barley worldwide (Del Ponte et al. 2015; Kelly and Ward 2018), and is the most frequent cause of GER and GSR in North America (Kuhnem et al. 2015). However in South America, including in northwestern Argentina and in the south of Brazil, as well as in Nepal, Fmer is more prevalent as the causal agent of GER and GSR (Desjardins and Proctor 2011; Kuhnem et al. 2016; Sampietro et al. 2011).

Previous reports have shown that aggressiveness-related traits contribute to shaping the profile of regional populations that co-exist and are shared among different cereal crops. The role of differential aggressiveness has been studied previously in wheat involving a larger set of FGSC species (Goswami and Kistler 2005; Nicolli et al. 2015, 2018; Spolti et al. 2012). These experiments showed that Fgra, which dominates on wheat, was also more aggressive than these other species on wheat. However, there are relatively few experiments looking at this question in maize. In one example, F. boothi, a DON/15-ADON producer that was the most prevalent species in field surveys in South Africa, was more aggressive and produced higher levels of mycotoxins compared with 
DON-producing wheat isolates of Fgra and NIV-producing Fmer (Beukes et al. 2018).

To test the hypothesis that Fmer is more aggressive than Fgra on maize, three experiments were conducted in the south (subtropical summer), and one in the central-south (tropical winter) of Brazil, totaling seven conditions (year $\times$ location $\times$ hybrid). To our knowledge, this is the first detailed study to examine aggressiveness, competitiveness and mycotoxin production by Fmer and Fgra on maize ears in field experiments in Brazil. It extends previous work that compared inoculation methods and hybrid resistance using a mixture of Fmer isolates (Nerbass et al. 2015; 2016). Using mixtures of two representative strains of each of the two species, our results supported our hypothesis that enhanced aggressiveness and competitiveness of Fmer is an important contributor to its dominance as the major GER pathogen in the country (Kuhnem et al. 2016). This conclusion does not preclude roles for other aspects of fitness and competitiveness in this observed dominance: for example Fmer may produce more ascospores or conidia, or it may survive better as a saprophyte on crop debris, or on alternative hosts. Further experiments will be needed to investigate the potential impact of these factors.

In our experiments conducted during the summer in the south of the country, we found that GER severity was, on average, twice as high when Fmer was inoculated alone, compared with solo inoculations of Fgra. During the period following the inoculations, mean temperature fluctuated between 20 and $25^{\circ} \mathrm{C}$, which was higher than the mean temperatures the crop experienced during the tropical winter in the Viçosa trial, where the relative humidity was 
also lower than in the south trials. The difference in GER severity between the species was reduced, but still significant, in the tropical winter trial where the inoculated plants experienced temperatures of around $5^{\circ} \mathrm{C}$ right after the inoculation. Two sequential inoculations, six days apart, performed only in the tropical winter trial, produced higher levels of disease for both species, with FmernFmer producing more disease than FgranFgra. Thus, results in all locations supported the hypothesis that Fmer is more aggressive on maize.

The overall increase in disease severity in the southern experiments is in agreement with several previous studies that, contrary to suggestions that GER is a disease of cooler weather (Munkvold 2003b), also reported increased severity or fungal growth under wetter and warmer temperatures $\left(20\right.$ to $\left.30^{\circ} \mathrm{C}\right)$ (Sutton 1982; Dalla Lana et al. 2020). A previous study involving two strains of each species reported that Fgra grew faster than Fmer at $25^{\circ} \mathrm{C}$ and $30^{\circ} \mathrm{C}$, whereas growth rates were similar at 10,15 or $20^{\circ} \mathrm{C}$ (Spolti et al. 2012). However, a more recent study using 20 strains from each species showed a wide variation in growth rates among isolates of the same species at both at 15 and $25^{\circ} \mathrm{C}$ (Kuhnem et al. 2016). Thus, the response to temperature is isolate-specific rather than species-specific, implying that the increased disease severity observed in the southern experiments is not due to a direct effect of temperature on the growth of Fgra versus Fmer. Further experiments are needed to explore whether the maize hybrid played a role in the disease outcomes in the different locations, as had been reported in other studies (Nerbass et al. 2016). 
Sequential alternate co-inoculation of maize ears with Fgra and Fmer suggested an antagonistic behavior, as this treatment generally produced lower disease levels than Fmer inoculated alone once, or sequentially twice. Results of mycotoxin assays suggested that Fmer was more competitive in co-inoculations if it was inoculated after, versus before Fgra. Both disease severity and NIV production were reduced when Fgra was inoculated into the same ear six days later, versus when Fmer was inoculated alone or sequentially twice. This suggests that growth of Fmer was suppressed by the growth of Fgra. In contrast, when Fgra was the first to colonize the inoculated site, neither DON nor ZEA was detected, suggesting that growth of Fgra was prevented by subsequent inoculation of Fmer. However, if Fgra was inoculated sequentially twice, it produced much more DON and higher disease severities than when it was followed by Fmer. Interestingly, in this case GER severity was higher than when either species was inoculated alone, or when Fmer was inoculated first. Damage caused by the initial inoculation with Fgra may have had an effect similar to wounding caused by lepidopteran larvae, acting as a breach to facilitate colonization by a second inoculation with Fmer or Fgra (Picot et al. 2012). The higher overall toxin concentration in ears infected by Fgra versus Fmer may be due to a generally higher amount of toxin produced by Fgra, as reported in previous comparative studies (Nicolli et al. 2015; Goswami and Kistler 2005; Tóth et al. 2005). Although the mycotoxin results represent only a single experiment, they suggest that interspecies interactions can have significant qualitative and quantitative effects on mycotoxin contamination in maize ears infected by GER. Further research is needed to better understand the role of these interactions in 
co-inoculations. In addition, it would be instructive to design and test specific markers to measure DNA content as a surrogate for biomass of each species (Vegi et al. 2011; Demeke et al. 2010), since they cannot be distinguished based on symptoms alone.

Our results suggest that breeders should consider carefully the inoculum they use during screening for resistance. Inoculum should represent strains and species that are dominant in the region where the hybrids will be deployed (Nerbass et al. 2016). It will also be important to test the significance of the species x hybrid interaction using a larger number of host genotypes. Data on this aspect in several wheat genotypes inoculated with Fgra or Fmer, where no significant species-cultivar interaction was found, was recently published (Mendes et al. 2018).

This study provides the first direct evidence of the ability of Fmer causing GER in Brazil to produce NIV in maize ears. This mycotoxin was recently reported to be the most frequent in surveys of commercial maize in Brazil (Oliveira et al. 2017). This finding confirms the importance of this pathogen in GER epidemics, and the need to include analysis of NIV mycotoxin, which is currently not a target for regulation, and lacking in routine mycotoxin surveys of Brazilian maize.

\section{Acknowledgements}

F. J. Machado thanks the Programa de Pós-graduação em Fitopatologia (UFV), CNPq-Conselho Nacional de desenvolvimento Científico e Tecnológico for 
providing a graduate scholarship and CAPES-Coordenação de Aperfeiçoamento de Pessoal de Nível Superior for providing a sandwich fellowship. P. Kuhnem thanks the Programa de Pós-graduação em Fitotecnia (UFRGS) and CNPq for providing a graduate scholarship. Thanks are given to CNPq for providing a research fellowship to E. M. Del Ponte and R. T. Casa. This work was partially supported by the National Institute of Food and Agriculture, U.S. Department of Agriculture, Multistate Project \#1008664.

\section{Data availability statement}

\section{Conflict of interest}

\section{Author contribution}

FJM and PRK conceived and conducted the field experiments, analysed the data and wrote the manuscript. RTC, DGSIII and NM conducted experiments and reviewed the manuscript. LJV and EMD conceived, wrote and submitted the manuscript.

\section{References}

Anvisa, 2011. Agência Nacional de Vigilância Sanitária. Resolução da diretoria colegiada- $\quad$ RDC $\mathrm{n}^{\circ} \quad 7, \quad$ de 26 de fevereiro de 2011. 
https://www.gov.br/agricultura/pt-br/assuntos/inspecao/produtos-vege tal/legislacao-1/RDC72011micotoxinas.pdf [Accessed October 16, 2020].

Anvisa, 2017. Agência Nacional de Vigilância Sanitária. Resolução da diretoria colegiada- RDC $\mathrm{n}^{\circ}$ 138, de 08 de fevereiro de 2017. http://bvsms.saude.gov.br/bvs/saudelegis/anvisa/2017/rdc0138_08_02_ 2017.pdf [Accessed October 16, 2020].

Anderson, N. R., Ravellette, J. D., and Wise, K. A. 2016. Improved method for injecting fungal inoculum into corn ears. Plant Health Progress. 17:163-166.

Anderson, N. R., Romero Luna, M. P., Ravellette, J. D., and Wise, K. A. 2017. Impact of foliar fungicides on Gibberella ear rot and deoxynivalenol levels in Indiana corn. Plant Health Progress. 18:186-191.

Andriolli, C. F., Casa, R. T., Kuhnem, P. R., Bogo, A., Zancan, R. L., and Reis, E. M. 2016. Timing of fungicide application for the control of Gibberella ear rot of maize. Trop. plant pathol. 41:264-269.

Bai, G.-H., Desjardins, A., and Plattner, R. 2002. Deoxynivalenol-nonproducing Fusarium graminearum causes initial infection, but does not cause disease spread in wheat spikes. Mycopathologia. 153:91-98.

Basler, R. 2016. Diversity of Fusarium species isolated from UK forage maize and the population structure of F. graminearum from maize and wheat. PeerJ. 4:e2143.

Beukes, I., Rose, L. J., van Coller, G. J., and Viljoen, A. 2018. Disease development and mycotoxin production by the Fusarium graminearum species complex associated with South African maize and wheat. European Journal of Plant Pathology. 150:893-910.

Boutigny, A.-L., Ward, T. J., Van Coller, G. J., Flett, B., Lamprecht, S. C., O’Donnell, K., and Viljoen, A. 2011. Analysis of the Fusarium graminearum species complex from wheat, barley and maize in South Africa provides evidence of species-specific differences in host preference. Fungal Genetics and Biology. 48:914-920.

Burlakoti, R. R., Tamburic-Ilincic, L., Limay-Rios, V., and Burlakoti, P. 2017. 
Comparative population structure and trichothecene mycotoxin profiling of Fusarium graminearum from corn and wheat in Ontario, central Canada. Plant Pathol. 66:14-27.

Carter, J. P., Rezanoor, H. N., Desjardins, A. E., and Nicholson, P. 2000. Variation in Fusarium graminearum isolates from Nepal associated with their host of origin. Plant Pathology. 49:452-460.

Castañares, E., Dinolfo, M. I., Del Ponte, E. M., Pan, D., and Stenglein, S. A. 2016. Species composition and genetic structure of Fusarium graminearum species complex populations affecting the main barley growing regions of South America. Plant Pathology. 65:930-939.

Chiotta, M. L., Zanon, M. S. A., Palazzini, J. M., Scandiani, M. M., Formento, A. N., Barros, G. G., and Chulze, S. N. 2016. Pathogenicity of Fusarium graminearum and F. meridionale on soybean pod blight and trichothecene accumulation. Plant Pathology. 65:1492-1497.

Dalla Lana, F., Madden, L. V., and Paul, P. A. 2020. Natural occurrence of maize Gibberella ear rot and contamination of grain with mycotoxins in association with weather variables. Plant Disease. Available at: https://apsjournals.apsnet.org/doi/abs/10.1094/PDIS-05-20-0952-RE [Accessed October 16, 2020].

Del Ponte, E. M., Spolti, P., Ward, T. J., Gomes, L. B., Nicolli, C. P., Kuhnem, P. R., Silva, C. N., and Tessmann, D. J. 2015. Regional and field-specific factors affect the composition of Fusarium Head Blight pathogens in subtropical no-till wheat agroecosystem of Brazil. Phytopathology. 105:246-254.

Demeke, T., Gräfenhan, T., Clear, R. M., Phan, A., Ratnayaka, I., Chapados, J.,Patrick, S. K., Gaba, D., Lévesque, C. A., and Seifert, K. A. 2010. Development of a specific TaqMan® real-time PCR assay for quantification of Fusarium graminearum clade 7 and comparison of fungal biomass determined by PCR with deoxynivalenol content in wheat and barley. International Journal of Food Microbiology. 141:45-50.

Desjardins, A. E., and Proctor, R. H. 2011. Genetic diversity and trichothecene 
chemotypes of the Fusarium graminearum clade isolated from maize in Nepal and identification of a putative new lineage. Fungal Biology. 115:38-48.

Desjardins, A. E., Proctor, R. H., Bai, G., McCormick, S. P., Shaner, G., Buechley, G., and Hohn, T. M. 1996. Reduced virulence of trichothecene-nonproducing mutants of Gibberella zeae in wheat field tests. Molecular Plant-Microbe Interactions. 9:775-781.

van Egmond, H. P., Schothorst, R. C., and Jonker, M. A. 2007. Regulations relating to mycotoxins in food: Perspectives in a global and European context. Anal Bioanal Chem. 389:147-157.

Esker, P. D., Shah, D. A., Bradley, C. A., Conley, S. P., Paul, P. A., and Robertson, A. E. 2018. Perceptions of midwestern crop advisors and growers on foliar fungicide adoption and use in maize. Phytopathology. 108:1078-1088.

Fingstag, M. D., Casa, R. T., Bogo, A., Kuhnem, P., Sangoi, L., Valente, J. B.,Bevilaqua, D., Fiorentin, O. A., and Gonçalves, M. J. 2019. Fungicide performance on Fusarium meridionale control, grain yield and grain damage in maize. Summa phytopathol. 45:265-271.

Fox, J. and Weisberg, S. 2019. An $\{R\}$ Companion to Applied Regression, Third Edition. Thousand Oaks CA: Sage. Available at: https://socialsciences.mcmaster.ca/jfox/Books/Companion/ [Accessed October 16, 2020].

Fuentes, R. G., Mickelson, H. R., Busch, R. H., Dill-Macky, R., Evans, C. K., Thompson, W. G., Wiersma, J. V., Xie, W., Dong, Y., and Anderson, J. A. 2005. Resource allocation and cultivar stability in breeding for Fusarium Head Blight resistance in spring wheat. Crop Science. 45:1965-1972.

Gai, X. T., Xuan, Y. H., and Gao, Z. G. 2017. Diversity and pathogenicity of Fusarium graminearum species complex from maize stalk and ear rot strains in northeast China. Plant Pathology. 66:1267-1275.

Gomes, L. B., Ward, T. J., Badiale-Furlong, E., and Del Ponte, E. M. 2015. Species composition, toxigenic potential and pathogenicity of Fusarium graminearum species complex isolates from southern Brazilian rice. Plant 
Pathology. 64:980-987.

Goswami, R. S., and Kistler, H. C. 2004. Heading for disaster: Fusarium graminearum on cereal crops. Molecular Plant Pathology. 5:515-525.

Goswami, R. S., and Kistler, H. C. 2005. Pathogenicity and in planta mycotoxin accumulation among members of the Fusarium graminearum species complex on wheat and rice. Phytopathology. 95:1397-1404.

Harris, L. J., Desjardins, A. E., Plattner, R. D., Nicholson, P., Butler, G., Young, J. C., Weston, G., Proctor, R. H., and Hohn, T. M. 1999. Possible role of trichothecene mycotoxins in virulence of Fusarium graminearum on maize. Plant Disease. 83:954-960.

Hartig, F., and Lohse, L. 2020. DHARMa: Residual Diagnostics for Hierarchical (Multi-Level / Mixed) Regression Models. Available at: https://CRAN.R-project.org/package=DHARMa [Accessed October 16, 2020].

Kelly, A. C., and Ward, T. J. 2018. Population genomics of Fusarium graminearum reveals signatures of divergent evolution within a major cereal pathogen. PLOS ONE. 13:e0194616.

Kuhnem, P. R., Del Ponte, E. M., Dong, Y., and Bergstrom, G. C. 2015. Fusarium graminearum isolates from wheat and maize in New York show similar range of aggressiveness and toxigenicity in cross-species pathogenicity tests. Phytopathology. 105:441-448.

Kuhnem, P. R., Ward, T. J., Silva, C. N., Spolti, P., Ciliato, M. L., Tessmann, D. J., and Del Ponte, E. M. 2016. Composition and toxigenic potential of the Fusarium graminearum species complex from maize ears, stalks and stubble in Brazil. Plant Pathology. 65:1185-1191.

Lee, J., Kim, H., Jeon, J.-J., Kim, H.-S., Zeller, K. A., Carter, L. L. A., Leslie, J. and Lee, Y.-W. 2012. Population structure of and mycotoxin production by Fusarium graminearum from maize in South Korea. Applied and Environmental Microbiology. 78:2161-2167.

Lenth, R., Buerkner, P., Herve, M., Love, J., Riebl, H., and Singmann, H. 2020. 
emmeans: Estimated Marginal Means, aka Least-Squares Means. Available at: https://CRAN.R-project.org/package=emmeans [Accessed October 16, 2020].

Logrieco, A., Mulè, G., Moretti, A., and Bottalico, A. 2002. Toxigenic Fusarium species and mycotoxins associated with maize ear rot in Europe eds. A. Logrieco, J. A. Bailey, L. Corazza, and B. M. Cooke. European Journal of Plant Pathology. 108:597-609.

Luna, M. P. R., and Wise, K. A. 2015. Timing and efficacy of fungicide applications for Diplodia ear rot management in corn. Plant Health Progress. 16:123-131.

Maier, F. J., Miedaner, T., Hadeler, B., Felk, A., Salomon, S., Lemmens, M., Kassner, H., and Schäfer, W. 2006. Involvement of trichothecenes in fusarioses of wheat, barley and maize evaluated by gene disruption of the trichodiene synthase (Tri5) gene in three field isolates of different chemotype and virulence. Molecular Plant Pathology. 7:449-461.

McMullen, M., Bergstrom, G., De Wolf, E., Dill-Macky, R., Hershman, D., Shaner, G., and Van Sanford, D. 2012. A unified effort to fight an enemy of wheat and barley: Fusarium Head Blight. Plant Disease. 96:1712-1728.

Mendes, G. da R. L., Ponte, E. M. D., Feltrin, A. C., Badiale-Furlong, E., and Oliveira, A. C. de. 2018. Common resistance to Fusarium head blight in Brazilian wheat cultivars. Scientia Agricola. 75:426-431.

Mesterházy, Á., Lemmens, M., and Reid, L. M. 2012. Breeding for resistance to ear rots caused by Fusarium spp. in maize-a review. Plant Breeding. 131:1-19.

Miedaner, T., Schilling, A. G., and Geiger, H. H. 2004. Competition Effects Among Isolates of Fusarium culmorum Differing in Aggressiveness and Mycotoxin Production on Heads of Winter Rye. European Journal of Plant Pathology. 110:63-70.

Miller, J. D., and Greenhalgh, R. 1991. Trichothecene chemotypes of three Fusarium species. Mycologia. 83:121-130.

Mirocha, C. J., Kolaczkowski, E., Xie, W., Yu, H., and Jelen, H. 1998. Analysis of deoxynivalenol and Its derivatives (batch and single kernel) using gas 
chromatography/mass spectrometry. J. Agric. Food Chem. 46:1414-1418.

Munkvold, G. P. 2003a. Cultural and genetic approaches to managing mycotoxins in maize. Annu. Rev. Phytopathol. 41:99-116.

Munkvold, G. P. 2003b. Epidemiology of Fusarium diseases and their mycotoxins in maize ears. European Journal of Plant Pathology. 109:705-713.

Munkvold, G. P., Arias, S., Taschl, I., and Gruber-Dorninger, C. 2019. Mycotoxins in corn: occurrence, impacts, and management. In Corn, Elsevier, p. 235-287.

Ndoye, M., Zhang, J.-B., Wang, J.-H., Gong, A.-D., Li, H.-P., Qu, B., Li, S.-J., and Lia, Y.-C. 2012. Nivalenol and 15-acetyldeoxynivalenol chemotypes of Fusarium graminearum clade species are prevalent on maize throughout China. Journal of Phytopathology. 160:519-524.

Nerbass, F. R., Casa, R. T., Kuhnem, P. R., Bogo, A., Sangoi, L., Fingstag, M. D., Vieira Junior, J. A. L., and Stoltz, J. C. 2016. Evaluation of Fusarium graminearum inoculation methods in maize ears and hybrid reaction to Gibberella ear rot under southern Brazilian environmental conditions. Eur J Plant Pathol. 144:45-53.

Nerbass, F. R., Casa, R. T., Kuhnem, P. R., Vieira, Jr., J. A. L., and Valente, J. B. 2015. Field evaluation of maize for Gibberella ear rot resistance using silk channel and kernel inoculation with Fusarium meridionale. Tropical Plant Pathology. 40:388-393.

Nicolli, C. P., Spolti, P., Tibola, C. S., Fernandes, J. M. C., and Del Ponte, E. M. 2015. Fusarium head blight and trichothecene production in wheat by Fusarium graminearum and F. meridionale applied alone or in mixture at post-flowering. Tropical Plant Pathology. 40:134-140.

Nicolli, C. P., Machado, F. J., Spolti, P., and Del Ponte, E. M. 2018. Fitness traits of deoxynivalenol and nivalenol-producing Fusarium graminearum species complex strains from wheat. Plant Disease. 102:1341-1347.

O’Donnell, K., Ward, T. J., Geiser, D. M., Corby Kistler, H., and Aoki, T. 2004. Genealogical concordance between the mating type locus and seven other nuclear genes supports formal recognition of nine phylogenetically distinct 
species within the Fusarium graminearum clade. Fungal Genetics and Biology. 41:600-623.

Oldenburg, E., Höppner, F., Ellner, F., and Weinert, J. 2017. Fusarium diseases of maize associated with mycotoxin contamination of agricultural products intended to be used for food and feed. Mycotoxin Res. 33:167-182.

Oliveira, M. S., Rocha, A., Sulyok, M., Krska, R., and Mallmann, C. A. 2017. Natural mycotoxin contamination of maize (Zea mays L.) in the South region of Brazil. Food Control. 73:127-132.

Pereira, C. B., Ward, T. J., Del Ponte, E. M., Moreira, G. M., Busman, M., McCormick, S. P., and Feksa, H. R. 2021. Five-year survey uncovers extensive diversity and temporal fluctuations among Fusarium head blight pathogens of wheat and barley in Brazil. Plant Pathology. Available at: https://bsppjournals.onlinelibrary.wiley.com/doi/10.1111/ppa.13289 [Accessed October 16, 2020].

Pestka, J. J. 2010. Deoxynivalenol: mechanisms of action, human exposure, and toxicological relevance. Archives of Toxicology. 84:663-679.

Picot, A., Hourcade-Marcolla, D., Barreau, C., Pinson-Gadais, L., Caron, D., Richard-Forget, F., and Lannou, C. 2012. Interactions between Fusarium verticillioides and Fusarium graminearum in maize ears and consequences for fungal development and mycotoxin accumulation. Plant Pathology. 61:140-151.

R Core Team. 2020. R: A Language and Environment for Statistical Computing. Vienna, Austria: R Foundation for Statistical Computing. Available at: http://www.R-project.org/.

Reid, L., Hamilton, R., and Mather, D. 1995. Effect of macroconidial suspension volume and concentration on expression of resistance to Fusarium graminearum in maize. Plant disease. 79:461-466.

Reid, L. M., Nicol, R. W., Ouellet, T., Savard, M., Miller, J. D., Young, J. C., Stewart, D. W., and Schaafsma, A. W. 1999. Interaction of Fusarium graminearum and F. moniliforme in maize ears: disease progress, fungal biomass, and 
mycotoxin accumulation. Phytopathology. 89:1028-1037.

Reid, L. M., Woldemariam, T., Zhu, X., Stewart, D. W., and Schaafsma, A. W. 2002. Effect of inoculation time and point of entry on disease severity in Fusarium graminearum, Fusarium verticillioides, or Fusarium subglutinans inoculated maize ears. Canadian Journal of Plant Pathology. 24:162-167.

Reid, L. M., and Zhu, X. 2005. Screening Corn for Resistance to Common Diseases in Canada. Available at: http://publications.gc.ca/collections/Collection/A42-103-2005E.pdf. [Accessed October 16, 2020].

Rocha, O., Ansari, K., and Doohan, F. M. 2005. Effects of trichothecene mycotoxins on eukaryotic cells: A review. Food additives and contaminants. 22:369-378.

Sampietro, D. A., Díaz, C. G., Gonzalez, V., Vattuone, M. A., Ploper, L. D., Catalan, C. A. N., and Ward, T. 2011. Species diversity and toxigenic potential of Fusarium graminearum complex isolates from maize fields in northwest Argentina. International Journal of Food Microbiology. 145:359-364.

Siou, D., Gélisse, S., Laval, V., Elbelt, S., Repinçay, C., Bourdat-Deschamps, M., Suffert, F., and Lannou, C. 2015. Interactions between head blight pathogens: consequences for disease development and toxin production in wheat spikes. Appl. Environ. Microbiol. 81:957-965.

Spolti, P., Barros, N. C., Gomes, L. B., dos Santos, J., and Del Ponte, E. M. 2012. Phenotypic and pathogenic traits of two species of the Fusarium graminearum complex possessing either 15-ADON or NIV genotype. European Journal of Plant Pathology. 133:621-629.

Stumpf, R., Santos, J. dos, Gomes, L. B., Silva, C. N., Tessmann, D. J., Ferreira, F. D., Machinski Junior, M. and Del Ponte, E. M. 2013. Fusarium species and fumonisins associated with maize kernels produced in Rio Grande do Sul State for the 2008/09 and 2009/10 growing seasons. Brazilian Journal of Microbiology. 44:89-95.

Sutton, J. C. 1982. Epidemiology of wheat head blight and maize ear rot caused 
by Fusarium graminearum. Canadian Journal of Plant Pathology. 4:195-209.

Tóth, B., Mesterházy, Á., Horváth, Z., Bartók, T., Varga, M., and Varga, J. 2005. Genetic variability of central European isolates of the Fusarium graminearum species complex. Eur J Plant Pathol. 113:35-45.

Umpiérrez-Failache, M., Garmendia, G., Pereyra, S., Rodríguez-Haralambides, A., Ward, T. J., and Vero, S. 2013. Regional differences in species composition and toxigenic potential among Fusarium head blight isolates from Uruguay indicate a risk of nivalenol contamination in new wheat production areas. International Journal of Food Microbiology. 166:135-140.

Vaughan, M. M., Ward, T. J., McCormick, S. P., Orwig, N., Hay, W. T., Proctor, R., and Palmquist, D. 2020. Intrapopulation antagonism can reduce the growth and aggressiveness of the wheat head blight pathogen Fusarium graminearum. Phytopathology. 110:916-926.

Vegi, A., Schwarz, P., and Wolf-Hall, C. E. 2011. Quantification of Tri5 gene, expression, and deoxynivalenol production during the malting of barley. International Journal of Food Microbiology. 150:150-156.

Wagacha, J. M., Oerke, E.-C., Dehne, H.-W., and Steiner, U. 2012. Interactions of Fusarium species during prepenetration development. Fungal Biology. 116:836-847.

Walkowiak, S., Bonner, C. T., Wang, L., Blackwell, B., Rowland, O., and Subramaniam, R. 2015. Intraspecies Interaction of Fusarium graminearum Contributes to Reduced Toxin Production and Virulence. Molecular Plant-Microbe Interactions. 28:1256-1267.

Ward, T. J., Bielawski, J. P., Kistler, H. C., Sullivan, E., and O’Donnell, K. 2002. Ancestral polymorphism and adaptive evolution in the trichothecene mycotoxin gene cluster of phytopathogenic Fusarium. Proceedings of the National Academy of Sciences. 99:9278-9283.

Xu, X.-M., Monger, W., Ritieni, A., and Nicholson, P. 2007. Effect of temperature and duration of wetness during initial infection periods on disease development, fungal biomass and mycotoxin concentrations on wheat 
inoculated with single, or combinations of, Fusarium species. Plant Pathology. 56:943-956.

Zhang, H., Brankovics, B., Luo, W., Xu, J., Xu, J. S., Guo, C., Guo, J. G., Jin, S. L., Chen, W. Q., Feng, J., Van Diepeningen, A. D., Van der Lee, T. A. J. and Waalwijk, C. 2016. Crops are a main driver for species diversity and the toxigenic potential of Fusarium isolates in maize ears in China. World Mycotoxin Journal. 9:701-715. 


\section{SUPPLEMENTARY MATERIAL}

\section{FIGURES}
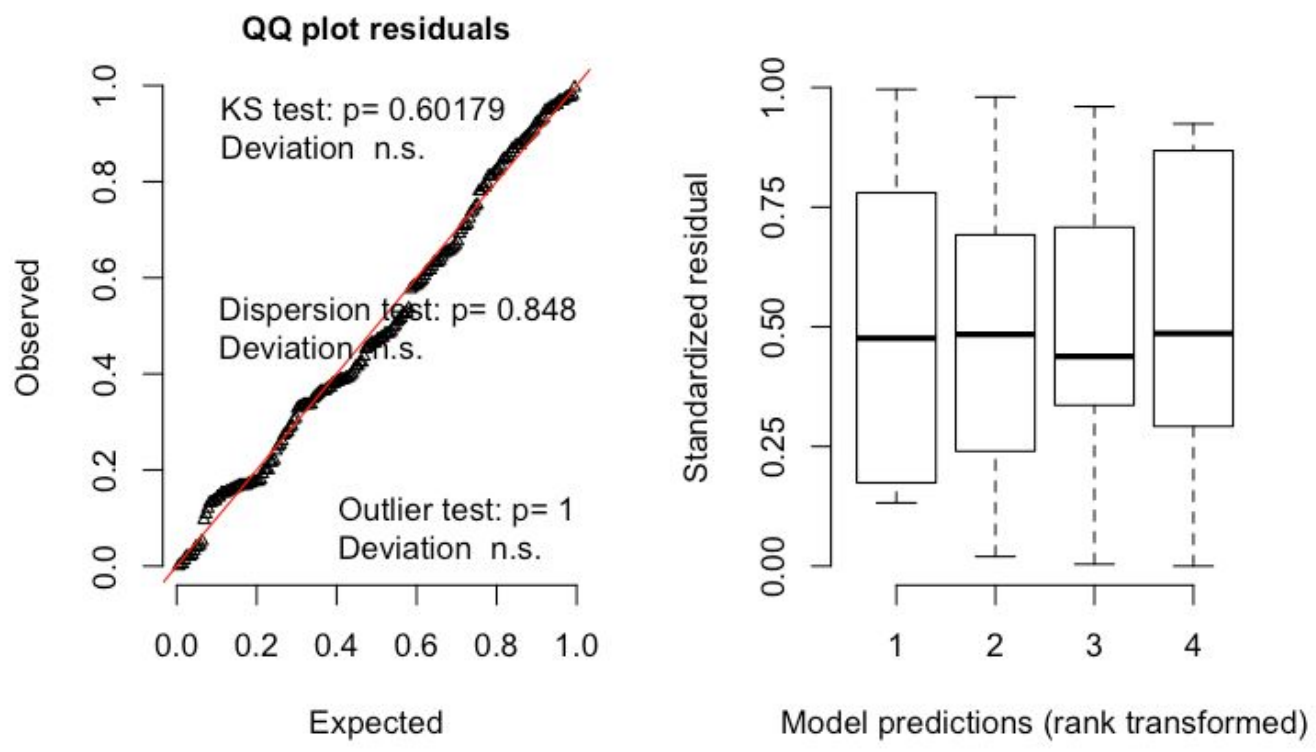

Figure S1. Visual outputs of the residual analysis by plot.DHARMa() function of the DHARMa R package for the model fitted to the six environments in the South trial. The plotQQunif() function (left) to detect overall deviations from the expected distribution with added P-values of tests for correct distribution (KS test), dispersion and outliers. The plotResiduals() function produces a plot (right) of the residuals against the predicted value (or alternatively, other variable). 


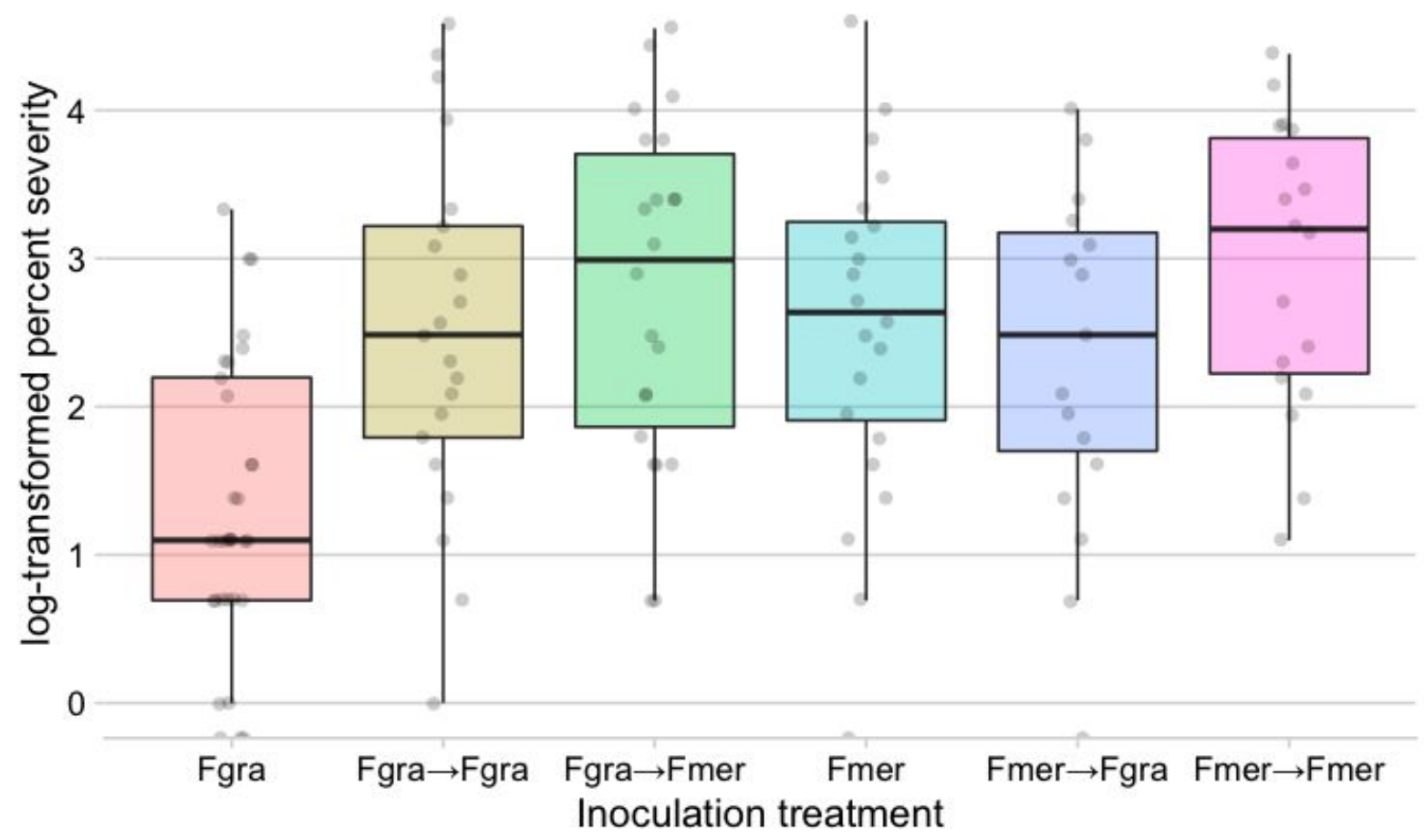

Figure S2. Distribution of log-transformed Gibberella ear rot (GER) visual severity estimates on individual plants (ear, dot) inoculated with inoculation treatments composed of single-time inoculation of either Fusarium graminearum (Fgra) or F. meridionale (Fmer) or sequential (second 6 days after the first) inoculation of the same species (Fgra2x or Fmer2x) or sequential alternated inoculation of the same species in different order (Fgra $\rightarrow$ Fmer or Fmer $\rightarrow$ Fgra). The RB9004 PRO2 ${ }^{\circledR}$ maize hybrid was cultivated during the 2017 growing season in Viçosa, Minas Gerais state (MG). 

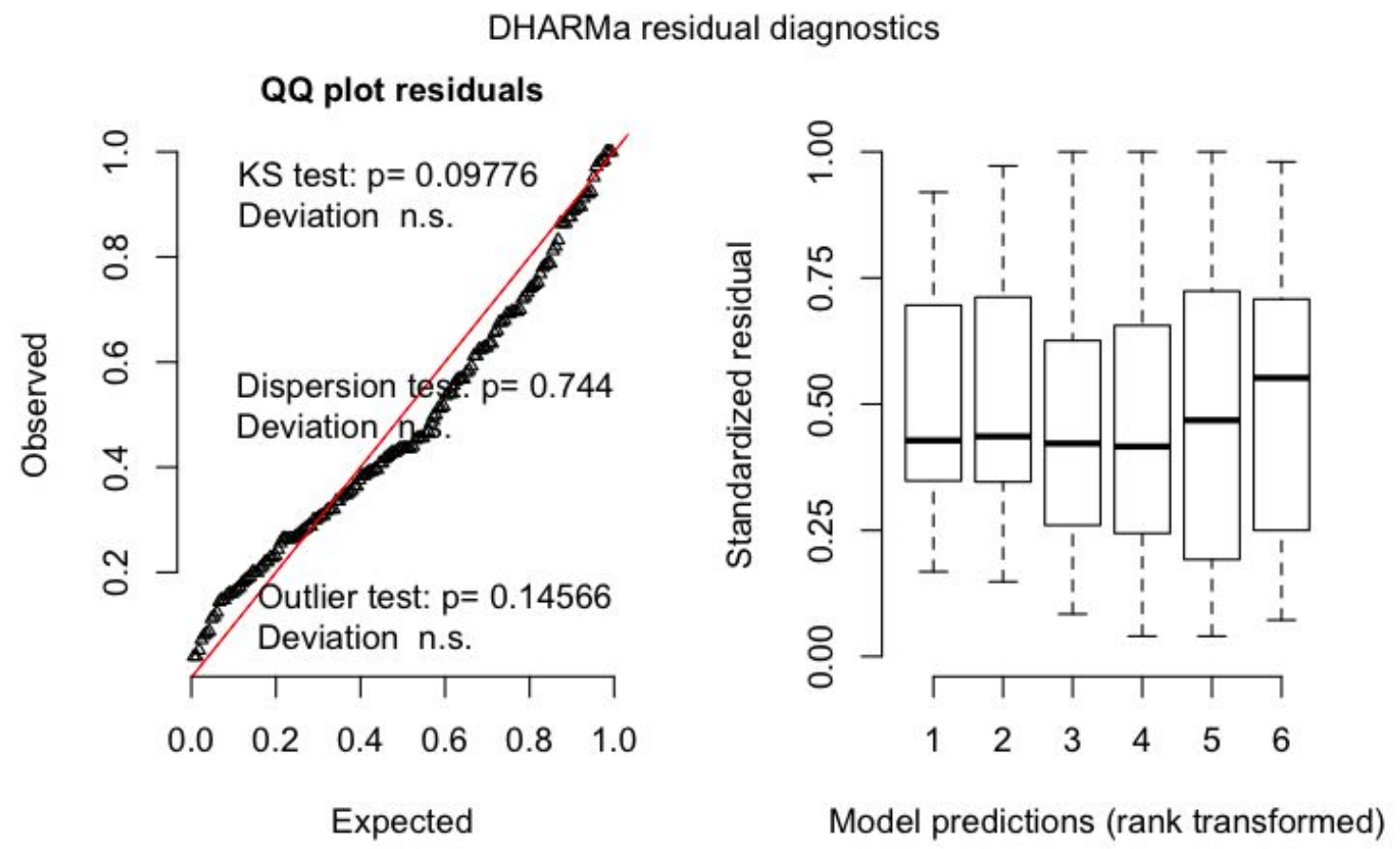

Figure S3. Visual outputs of the residual analysis by plot.DHARMa() function of the DHARMa R package for the model fitted to GER data from the Viçosa trial. The plotQQunif() function (left) to detect overall deviations from the expected distribution with added P-values of tests for correct distribution (KS test), dispersion and outliers. The plotResiduals() function produces a plot (right) of the residuals against the predicted value (or alternatively, other variable). 


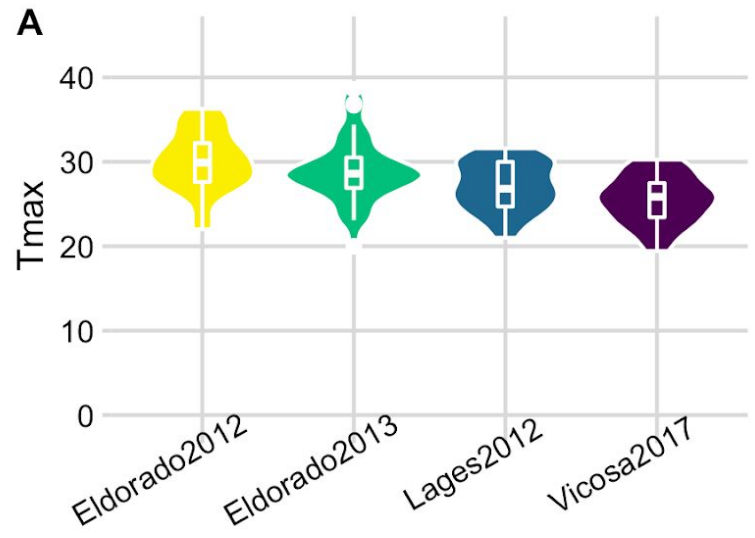

Trial

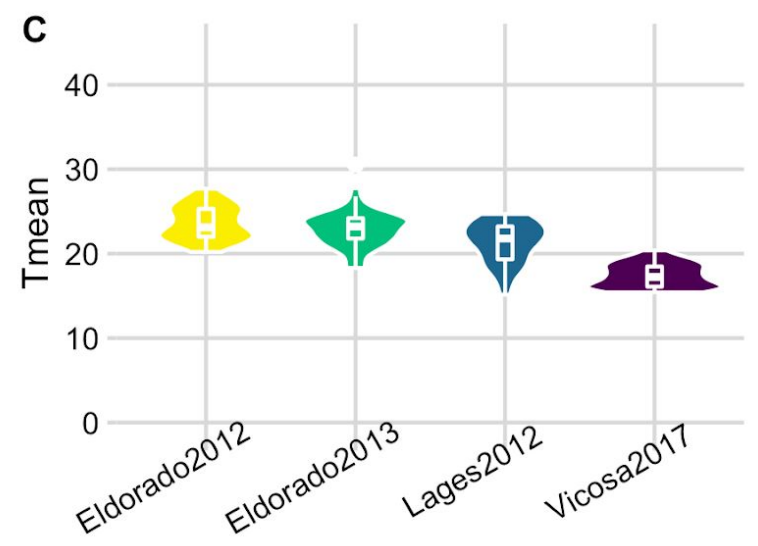

Trial

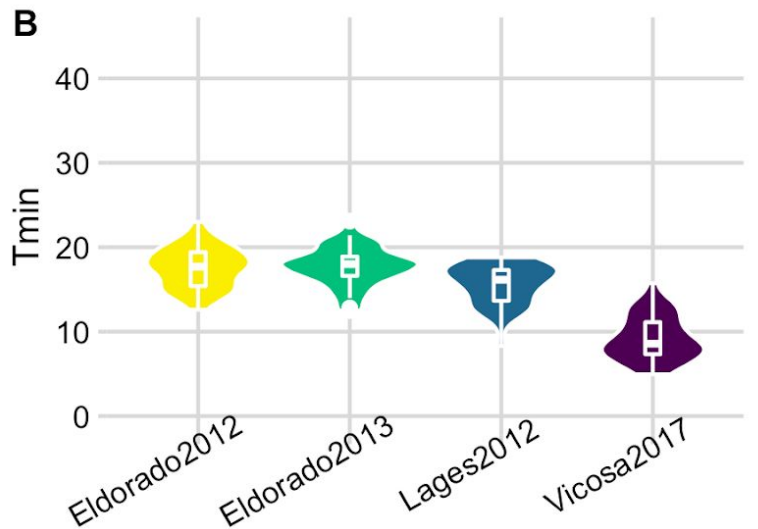

Trial

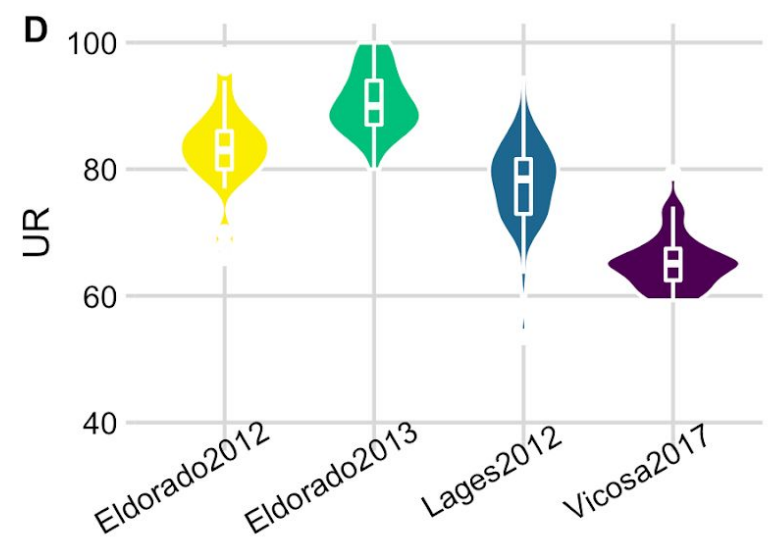

Trial

Figure S4. Violin-plots and box-plots (median and upper-lower quartile) for the distribution of temperature (minimum, mean and maximum) and relative humidity recorded at the nearest meteorological station during a period of around a month after inoculation of maize. Experiments were conducted at four environments (site x year) in southern (Eldorado and Lages, 2012 and 2013 harvest year) and central-eastearn (Viçosa, 2017 harvest year) Brazil. 